\title{
Electron backscatter diffraction characterization of fatigue crack growth in laser metal wire deposited Ti-6Al-4V
}

\author{
Pia Åkerfeldt ${ }^{\mathrm{a}}$ \\ Magnus Hörnqvist Colliander ${ }^{\mathrm{b}}$ \\ Robert Pederson ${ }^{\mathrm{a}, \mathrm{c}}$ \\ Marta-Lena Antti ${ }^{\mathrm{c}}$ \\ ${ }^{a}$ Division of Materials Science, Luleå University of Technology, Sweden \\ ${ }^{\mathrm{b}}$ Department of Physics, Chalmers University of Technology, Sweden \\ ${ }^{\mathrm{c}}$ Department of Engineering Science, University West, Sweden
}

\begin{abstract}
By additive manufacturing (AM) there is a feasibility of producing near net shape components in basically one step from 3D CAD model to final product. The interest for AM is high and during the past decade a lot of research has been carried out in order to understand the influence from process parameters on the microstructure and furthermore on the mechanical properties. In the present study laser metal wire deposition of Ti-6Al-4V has been studied in detail with regard to its fatigue crack propagation characteristics. Two specimen orientations, parallel and perpendicular to the deposition direction, have been evaluated at room temperature and at $250^{\circ} \mathrm{C}$. No difference in the fatigue crack growth rate could be confirmed for the two specimen orientations. However, in the fractographic study it was observed that the tortuosity varied between certain regions on the fracture surface. The local crack path characteristic could be related to the alpha colony size and/or the crystallographic orientation. Moreover, large areas exhibiting similar crystallographic orientation were observed along the prior beta grain boundaries, which were attributed to the wide alpha colonies frequently observed along the prior beta grain boundaries.
\end{abstract}

\section{Introduction}

Additive manufacturing (AM) has gained large interest since it has the potential to produce customized near net shaped products and lower the material cost compared to conventional manufacturing methods. There are many AM processes available today using different heat sources and feedstock material, but common for all processes is that the wanted shape is built layer-by-layer according to a predefined building sequence that is related to the CAD model of the component. More specific for titanium alloys within the aerospace industry, the AM processes could reduce the buy-to-fly ratio significantly, which today could exceed $80 \%$ for conventional methods $[1,2]$. However, in order to implement AM in the aerospace industry, the understanding of the relationship between the process parameters, the microstructure, and the mechanical properties is crucial, and still there is a lot of research and development needed so that the wanted quality of the component can be repeatedly achieved and guaranteed.

The focus of the present study is on laser metal wire deposition (LMwD) of Ti-6Al-4V. In $\mathrm{LMwD}$ a laser heat source melts a metal wire into the wanted shape and it is in general an attractive AM process for larger structures in which a higher deposition rate is advantageous $[3,4]$. As for many other AM processes, the LMwD:ed Ti-6Al-4V exhibits anisotropic mechanical properties that vary depending on the specimen orientation within the built 
material $[5,6]$. In previous work, the tensile $[6,10]$ and the low cycle fatigue [9] properties have been evaluated with respect to two specimen orientations. This anisotropy could be related to several parameters such as grain boundary alpha $[7,8]$ and prevalence of defects [9]. Moreover, the building process renders large columnar prior beta grains because of a preferential dendritic growth during solidification in the beta phase, thus from a macroscopic perspective the prior beta grains could also be related to the anisotropic properties [10].

Concerning the high cycle fatigue behavior of LMwD Ti-6Al-4V, a tendency of difference in fatigue limit has been observed for the two specimen orientations [4, 11]. To date, no study on the fatigue crack growth on LMwD:ed Ti-6Al-4V is available in the literature to the authors knowledge. So far, only AM processes with powder used as feedstock material have been evaluated [12-17]. The main objective of the current work has been to characterize the crack profiles of fatigue crack growth fractured specimens, thereby increasing the understanding of the crack propagation behavior and the impact of microstructural features and crystallographic orientation on the crack path characteristics.

\section{Materials and Methods}

The material characterized in the current study was manufactured using laser metal wire deposition (LMwD) and comes from the same walls as in $[9,10]$. In the LMwD process a robotized fiber laser cell melts a metal wire layer by layer forming the wanted shape, which in this case was so called "walls". The composition of the Ti-6Al-4V wire was in accordance to the aerospace material specification AMS 4954 and the wire diameter was $1.14 \mathrm{~mm}$. The power of the laser during manufacturing was in between $2-3 \mathrm{~kW}$ and the manufacturing was carried out in a sealed atmosphere containing less than $20 \mathrm{ppm}$ oxygen. The walls were five beads thick (approximate $22 \mathrm{~mm}$ ) and had varying dimensions, from $110 \times 37 \times 22 \mathrm{~mm}$ to 110x106x22 mm, depending on number of specimens and specimen orientation. The walls were post weld heat treated and annealed at $704^{\circ}$ for two hours and cooled in the furnace to $538^{\circ} \mathrm{C}$, after which the samples were taken out of the furnace and air cooled to room temperature. This heat treatment is not expected to introduce any significant changes to the microstructure [18].

Fatigue crack growth testing was performed using the surface flawed $\mathrm{Kb}$ specimen geometry [19]. Cylindrical blanks with a diameter of $14 \mathrm{~mm}$ were machined from the walls with the longitudinal axis in the deposition direction ( $x$, denoted "parallel") or in the wall height direction ( $z$, denoted "perpendicular"). See schematic representation of the specimen orientation in the walls in Figure 1, left. The blanks were inertia welded to larger cylinders of forged Ti-6Al-4V at both ends to allow machining of the button-head grips. The final gauge section had a rectangular cross-section ( $W \times \mathrm{x} T$, where $W$ is the specimen width and $T$ is the thickness) of $10.2 \times 4.3 \mathrm{~mm}^{2}$, and a gauge length of $32 \mathrm{~mm}$ (Figure 1, right). The orientations of the $y$ and $z$ directions were tracked during the machining operations, ensuring that the wide face of the gauge sections lay in the $x-z$ plane. A notch was created in the middle of the gauge section, centered on the wide face, using EDM machining. 

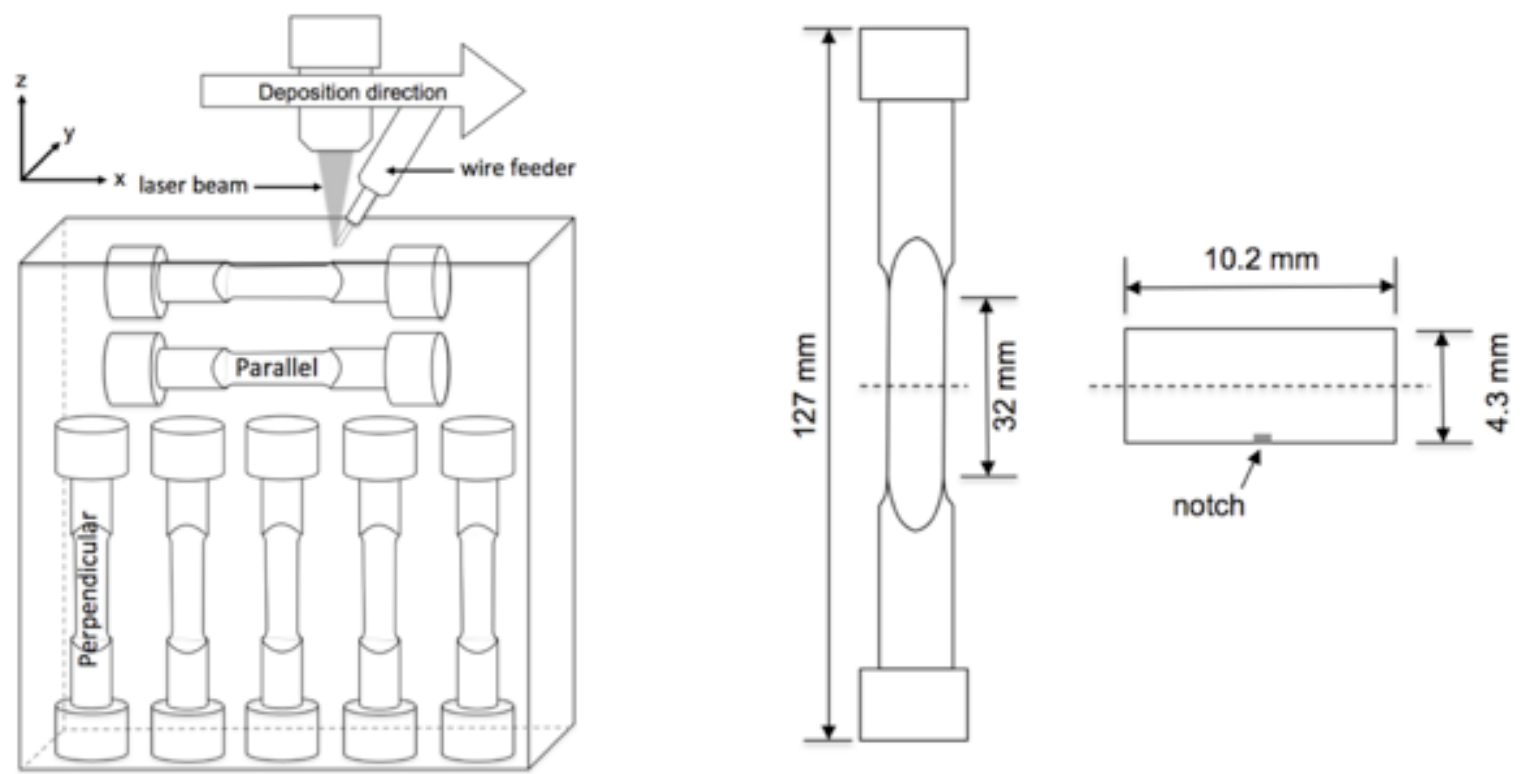

Figure 1. Schematic illustration showing the laser metal wire deposition process of a wall and the specimen orientations (left). The dimensions of the fatigue crack growth specimen and its cross section of the gauge section (right).

An initial semi-circular fatigue crack, approximately $0.7 \mathrm{~mm}$ in depth (except for specimen 2 where the pre-crack was $1.2 \mathrm{~mm}$ deep), was created from the notch by cyclic loading at a stress ratio $R=\sigma_{\min } / \sigma_{\max }=0$, a frequency $f=10 \mathrm{~Hz}$ and a maximum stress of $500 \mathrm{MPa}$. Thereafter, fatigue growth testing was performed at room temperature (RT) and $250{ }^{\circ} \mathrm{C}$ according to applicable parts of ASTM E647-08 and ASTM E740-03, under linear elastic fracture mechanics conditions. A triangular waveform was used, with $f=0.5 \mathrm{~Hz}$ and $R=0$ and maximum stress of $500 \mathrm{MPa}$ for RT tests and $325 \mathrm{MPa}$ for $250{ }^{\circ} \mathrm{C}$, in order to maintain a constant ratio of maximum stress to yield stress at the test temperature. The crack length was monitored using direct current potential drop (PD), with PD probes attached across the crack and reference probes at the back face of the specimen, away from the cracked cross-section. The PD signal was normalized by the reference signal and translated to crack length, $a$, based on a linear relationship between crack size and PD, which was experimentally verified prior to testing. The corresponding fatigue crack growth rate per cycle, $\mathrm{d} a / \mathrm{d} N$, was calculated according to the secant method in ASTM E647, and the stress intensity factor range, $\Delta K$, was calculated at the deepest point of the crack according to ASTM E740 assuming a semicircular shape of the crack. The tests were stopped at crack lengths around $2.5 \mathrm{~mm}$, and the specimens were subsequently fractured in tension at room temperature. Out of the tested specimens, three specimens were characterized in detail as described below; two parallel specimens tested at room temperature and $250^{\circ} \mathrm{C}$, respectively, and one perpendicular specimen tested at $250^{\circ} \mathrm{C}$. This alloy is used in aerospace applications where the working temperature varies from RT up to $250^{\circ} \mathrm{C}$. Therefore, the mechanical testing was performed both at the lower temperature (RT) and at the elevated working temperature $\left(250^{\circ} \mathrm{C}\right)$. The fracture surface of the perpendicular specimen at room temperature was damaged and thus not included in the detailed characterization.

Microstructural characterization was carried out on cross sections parallel to the fracture surface, about $8 \mathrm{~mm}$ away from the fracture surface. The fracture surface was carefully protected during cutting. The cross sections were ground and polished by conventional methods for titanium alloys and etched with Kroll's solution $\left(100 \mathrm{ml} \mathrm{H}_{2} \mathrm{O}, 2 \mathrm{ml} \mathrm{HNO}_{3}\right.$, and 1 $\mathrm{ml} \mathrm{HF}$ ) to reveal the microstructure. The microstructural characterization was performed in 
light optical microscope (Nikon eclipse MA200). Several images at 500 times magnification were stitched together using the software of the microscope (NIS Elements BR) enabling large area imaging at suitable magnification for microstructural characterization. The prior beta grain boundaries were thereafter manually highlighted using software for image editing (Adobe Photoshop CC 2015).

Fractographic analysis was performed on one half of the fractured specimen in the SEM (JEOL IT300LV and JEOL JSM 6064LV). Before fractographic analysis the fracture surfaces were cleaned in acetone in an ultra-sonic cleaner for 10 minutes. The fracture surface was characterized and documented and thereafter the locations of the crack profiles to be studied were decided. The specimens were carefully ground to the wanted position of the crack profile and thereafter polished by conventional methods for titanium alloys to a mirror-like surface for electron backscatter (EBSD) characterization. The location of the crack profile was confirmed in a stereomicroscope during preparation. Also the length of the pre-crack was measured in the stereomicroscope. The EBSD data was collected using an Oxford NordlysMax ${ }^{3}$ system and the data was processed using the HKL Channel 5 software. An acceleration voltage of $20 \mathrm{kV}$ was used during data acquisition and a step size of $1 \mu \mathrm{m}$ was used to characterize the orientation along the crack profile (at $150 \mathrm{x}$ magnification) while a step size of $0.5 \mu \mathrm{m}$ was used when certain areas were analyzed in detail at $400-800 \mathrm{x}$ magnification. The EBSD result is presented using inverse pole figure mapping that is colored relative to the normal direction of the fracture surface, i.e. in the loading direction of the specimen. Wild spikes were removed and a noise reduction of six neighbors was applied to all maps. Moreover, Schmid factor distribution maps were obtained from the EBSD data for the four primary slip systems of titanium, see Figure 2. Local misorientation maps were created by calculating the average misorientation with respect to neighboring pixels, the maximum allowable misorientation was set to $5^{\circ}$. For each local misorientation map the corresponding band contrast image was controlled in order to verify the image quality.

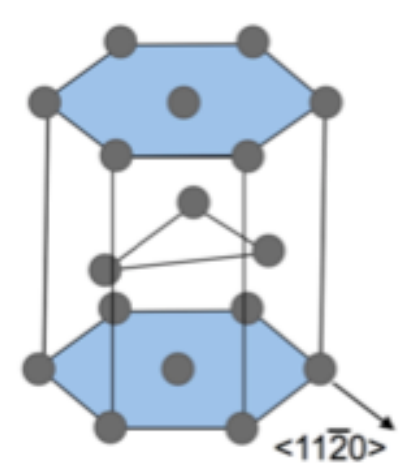

0001 slip plane (basal)

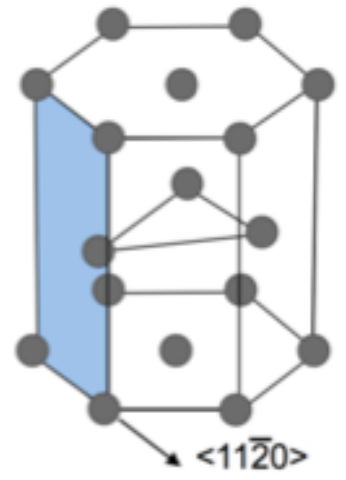

$10 \overline{1} 0$ slip plane (prismatic)

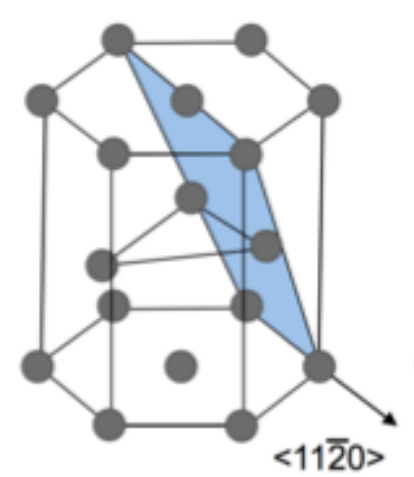

$10 \overline{1} 1$ slip plane (pyramidal)

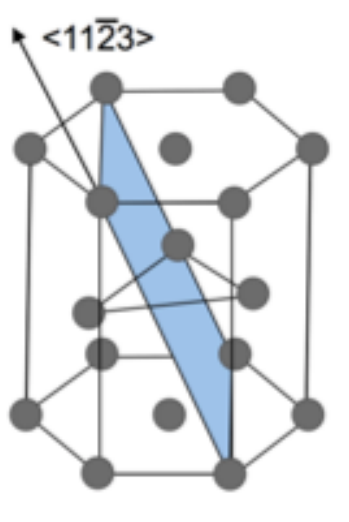

$11 \overline{2} 2$ slip plane (c+a)

Figure 2. The primary slip systems of alpha titanium.

\section{Results and discussion}

\subsection{Fatigue crack growth}

Figure 3 a) shows the development of the crack length with number of cycles. The higher rates observed at room temperature are caused by the higher maximum load. Note also the difference in starter crack size between the two room temperature specimens. Differences in 
load levels and starter crack size make it difficult to compare the different specimens. Therefore, the crack growth rate versus the stress intensity factor range is shown for all specimens in Figure $3 \mathrm{~b}$ ). The resulting crack growth rate curves are close to linear on a log$\log$ scale, indicating that the crack follows the expected power law behavior (Paris' law). At room temperature there is an observable difference between the two orientations, with the perpendicular specimen being approximately a factor 3 faster than the parallel, see Figure 3 b). However, this difference is within the level of scatter that can be expected from testing of coarse-grained material, and thus no firm conclusions can be drawn due to the low number of specimens tested here. For $250{ }^{\circ} \mathrm{C}$ the crack growth rates for the two orientations are virtually identical on a log-log scale (Figure $3 \mathrm{~b}$ )), and the difference in crack length with cycle number between specimens 1 and 3 in Figure 3 a) is only due to the accumulation of the small difference in propagation rates. Again, this is within the expected scatter between nominally identical specimens from a coarse grained material, no conclusions regarding the effect of specimen orientation on the crack growth behavior at $250{ }^{\circ} \mathrm{C}$ can be drawn. Furthermore, there is no significant difference between the crack growth rates at room temperature and $250^{\circ} \mathrm{C}$, as seen in Figure $3 \mathrm{~b}$ ).

a)

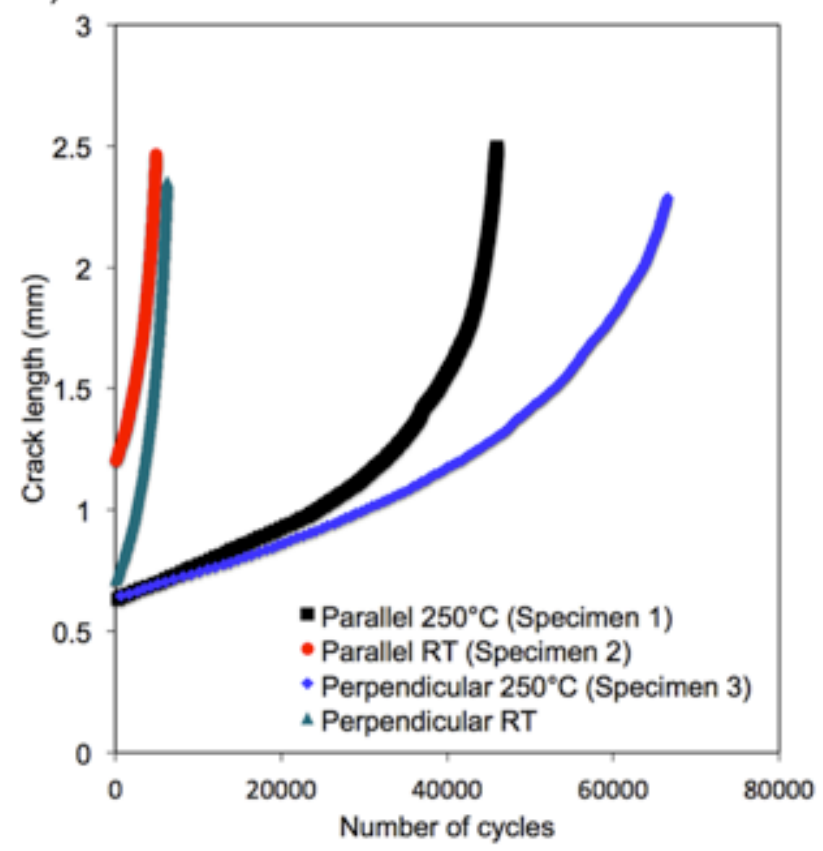

b)

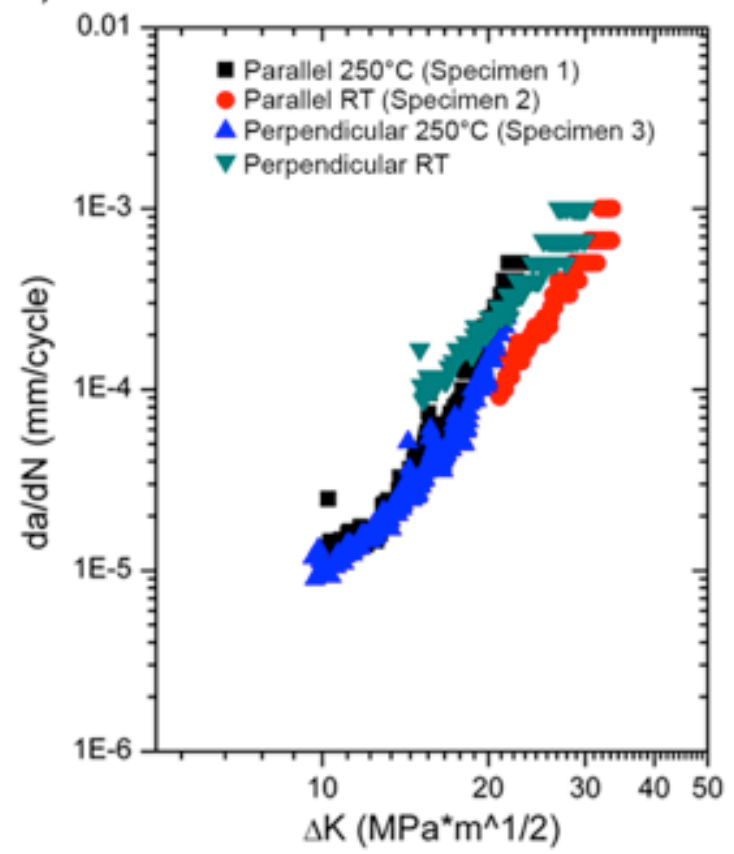

Figure 3. The crack length versus the number of cycles (left) and fatigue crack growth rate (right) for LMwD:ed Ti-6Al-4V parallel and perpendicular to deposition direction at room temperature and at $250^{\circ} \mathrm{C}$.

\subsection{Microstructural characterization}

The microstructure of the as-deposited material consists of large columnar prior beta grains growing through several deposited layers aligned with the thermal gradient in the material. Thus, the alignment of the prior beta grains will be varying with specimen orientation within the deposited wall. In Figure 4 cross sections parallel to the fracture surface are shown for three characterized specimens, with the notch located at the top edge of the cross section. For the two parallel test specimens it is clearly seen that the orientation of prior beta grains is similar, i.e. elongated along the cross section. It should be mentioned that the alignment of the prior beta grains at an angle of approximately $45^{\circ}$, see Figure 4 , in the current study is a result of the specimen machining and placement of the notch rather than the thermal gradient in the 
built material. In contrast and as expected, the cross sections of each individual prior beta grain are shown when characterizing the cross section of the perpendicular specimen, see Figure 4, right. Noteworthy is the large variation in size of the prior beta grains, from approximate $100 \mu \mathrm{m}$ to $2000 \mu \mathrm{m}$ in thickness (see Figure 4 specimen 1 and 2). This size variation is also seen on the perpendicular cross section (Figure 4 specimen 3 ).

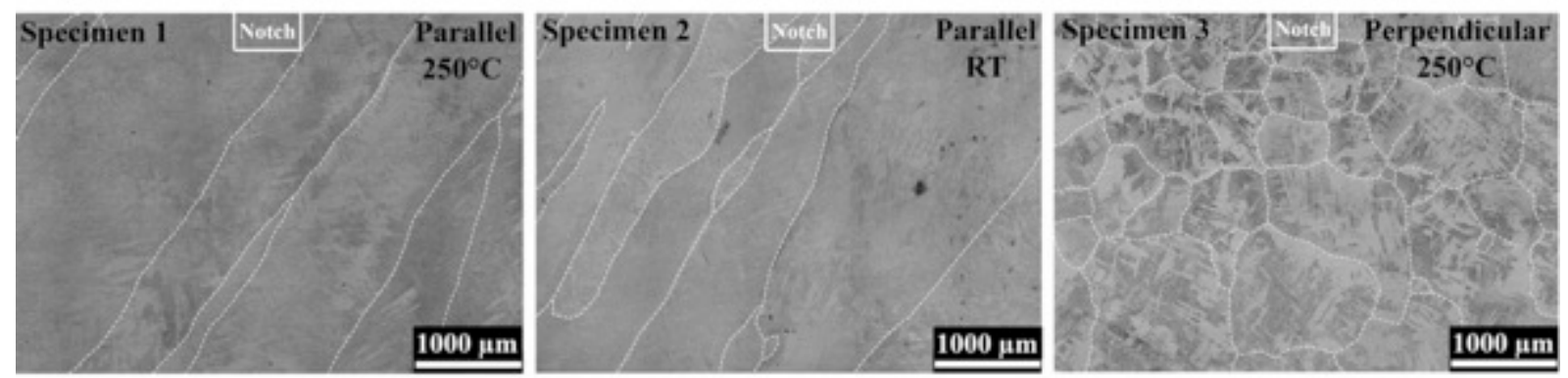

Figure 4. Micrographs of cross-sections in FCG specimen 1, 2, and 3 parallel to the fracture surface showing the orientation of columnar prior beta grains. White dashed lines highlight the prior beta grain boundaries.

At higher magnification, within the prior beta grains, the microstructure consists of fine alpha laths separated by retained beta. In Figure 5 the typical appearance of the different alpha structures is shown; the alpha laths are either observed as alpha colonies in which bundles of laths in the same orientation form a colony, or as basketweave alpha structure when there is arbitrary orientation of the alpha laths. Moreover, grain boundary alpha (GB alpha) is observed along the prior beta grain boundary (PB). In addition, areas with wide colony alpha are frequently observed next to the prior beta grain boundary. Regarding possible influence of specimen location (in the built wall) on microstructure for AM:ed material, no variation has been observed in this and previous studies on the same walls $[9,10]$.

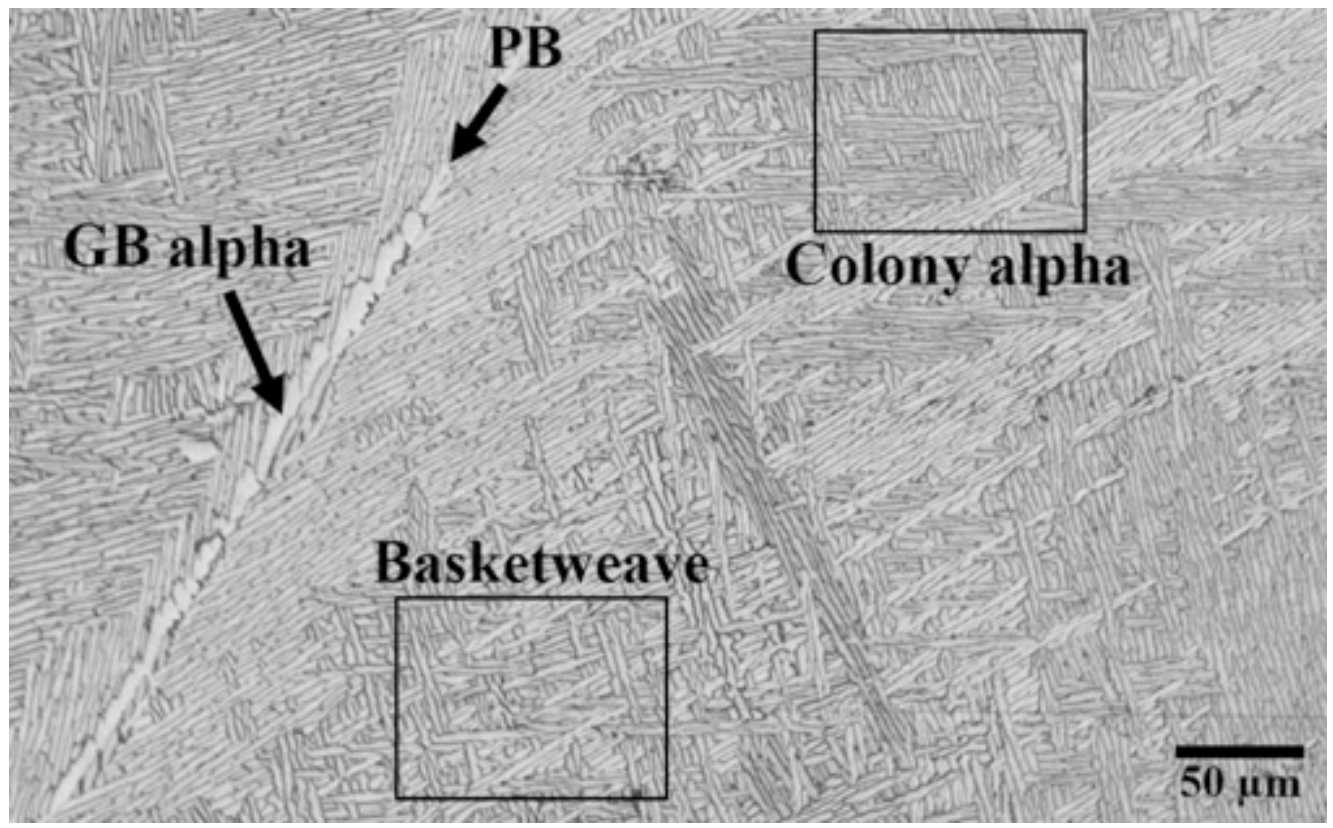

Figure 5. The microstructure within the prior beta grains consists of fine alpha laths forming alpha colonies and basketweave alpha microstructure. The prior beta grain boundary (PB) is decorated with grain boundary alpha (GB alpha) and closest to the grain boundary some areas of wide colony alpha are frequently observed. 


\subsection{Fractography}

In Figure 6 the fatigue crack propagation areas of the three evaluated specimens are shown. Common for all specimens is that certain regions of the fracture surface indicate a more serrated crack path. For instance, the left side of specimen 1 is rather flat compared to the right side; similarly the right side of specimen 2 is more flat than the left side. Moreover, features indicating the orientation of the columnar prior beta grains are observed on specimen 1 and 2, see features parallel to the arrows on the fracture surfaces. Also less distinct features are observed, for instance as shown by the hollow arrows in Figure 7 a), which is the flat area to the right of specimen 2 at higher magnification. In between these features believed to be prior beta grains there are ridges with higher tortuosity. Since the features and the indicated orientation of the columnar prior beta agree well with the microstructural characterization presented in Figure 4, the features are believed to be a reflection of the prior beta grains. Also on the fracture surface of specimen 3 , features indicating the location of prior beta grains are observed. The most pronounced area is seen next to the notch, indicated by an ellipse. Here a large plateau is seen with a similar size as the prior beta grains shown in Figure 4.
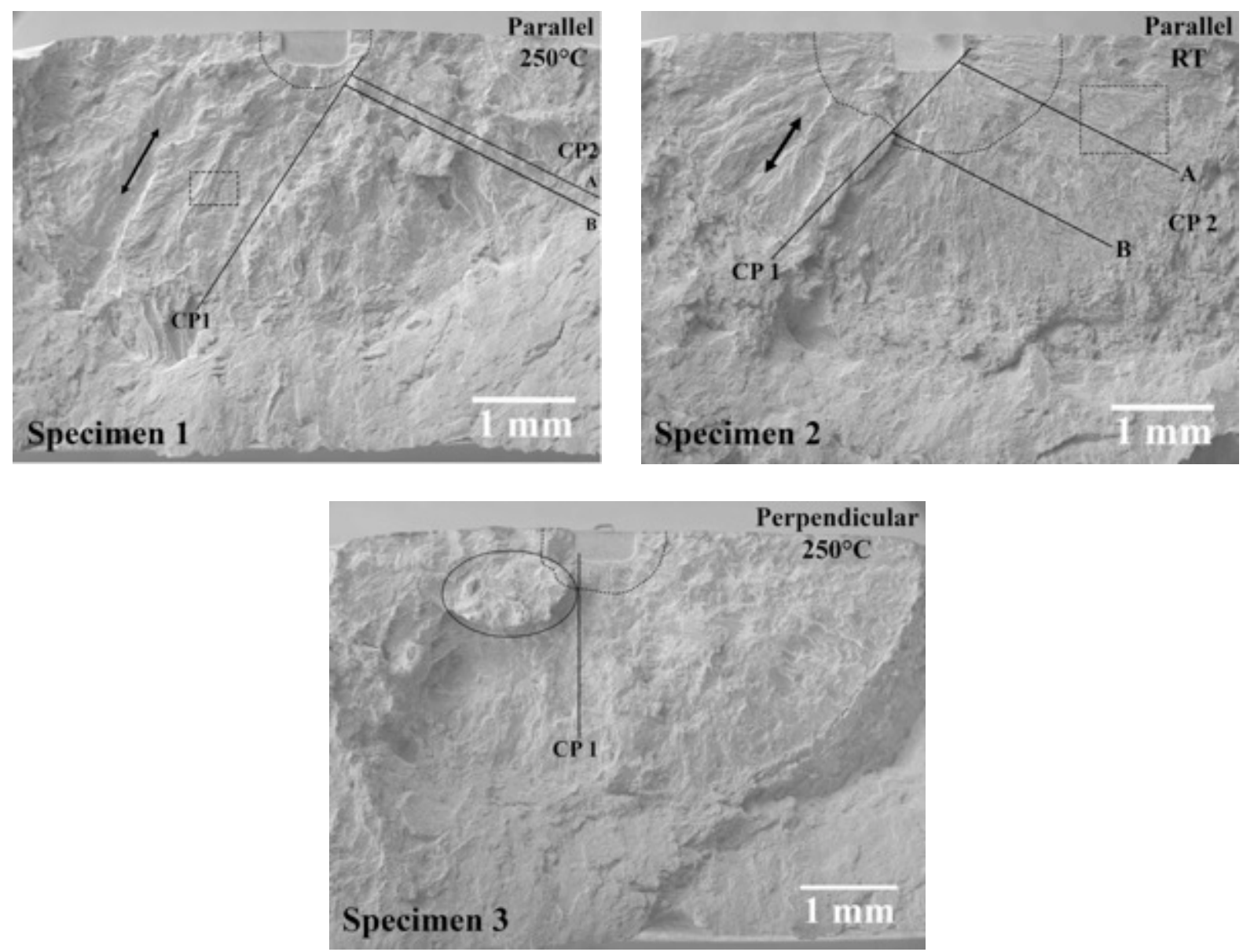

Figure 6. The fracture surfaces of specimen 1,2, and 3. The positions of the characterized crack profiles $(C P)$ are indicated in the fracture surface as well as the length of the pre-crack (black dotted lines). The arrows to the left in the fracture surfaces of specimen 1 and 2 indicate the orientation of the columnar prior beta grains determined after the fractographic study. The dashed squares on the fracture surface of specimen 1 and 2 indicate the location of Figure 7 b) and a) respectively. 

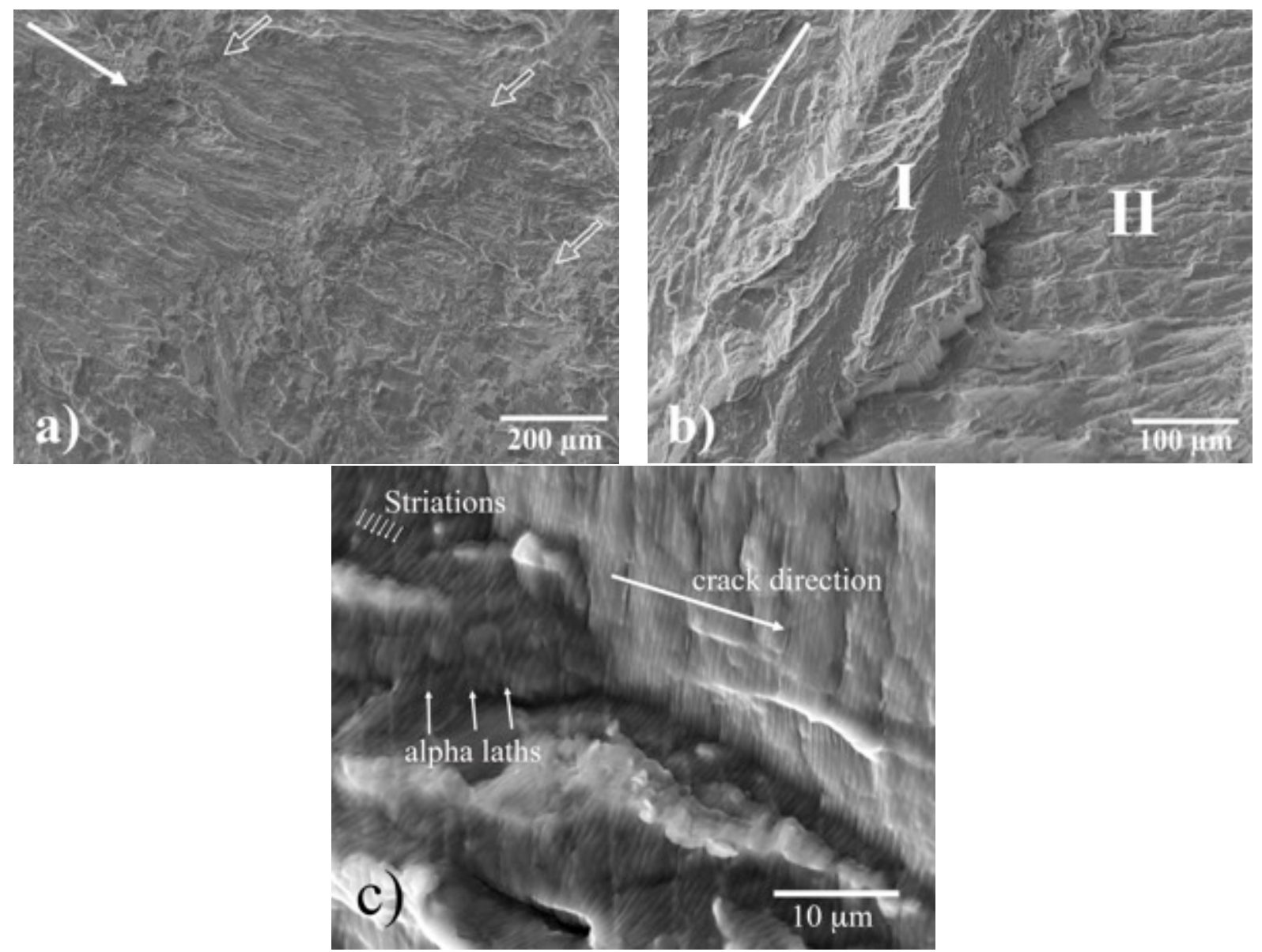

Figure 7. Features on the fracture surfaces indicating the orientation of the prior beta grains, here indicated by hollow arrows in a). The different crack path appearance in areas I and II could be attributed to different slip characteristics in specific prior beta grains. The solid white arrows indicate the crack growth direction in a) and b). The locations of a) and b) is indicated by dashed squares in Figure 6 in specimen 2 and 1, respectively. In c), striations normal to the crack direction, crossing the alpha laths, are shown from the fracture surface of specimen 2).

Furthermore, the crack path appearance varies for certain regions on the fracture surface, for instance the crack path through region I is different to that of region II in Figure $7 \mathrm{~b}$ ). From the crack path perspective, region I is smoother than II, which exhibits more staircase-like features along the crack path. The different appearance could be attributed to different slip characteristics in the different regions, which in this case as well as for the features on the fracture surface discussed above may be connected to the orientation of the prior beta grains since the features agree well with the orientation presented in Figure 4. Concerning the influence of test temperature, a smoother fracture surface is observed for the specimen tested at room temperature compared with the specimen of the same orientation tested at $250^{\circ} \mathrm{C}$, i.e. compare specimen 1 with specimen 2 . However, because of the limited number of specimens evaluated in the present study no further conclusions can be made regarding influence of test temperature. The pre-crack was generated at room temperature for all specimens, but in general no difference is observed between the pre-crack area and the area of the succeeding crack growth at $250^{\circ} \mathrm{C}$. More secondary cracks are observed for the perpendicular specimen compared to the two parallel specimens, regardless of temperature. A detailed observation of the striations were not possible to perform in the current study since $\mathrm{R}=0$ during testing and hence the striations are demolished and poorly shown on the fracture surface. However, in 
some areas the striations were observable, see Figure $7 \mathrm{c}$ ), indicating a ductile fatigue crack propagation.

\subsection{Crack profile characterization}

To further verify the orientation of the columnar prior beta grains, crack profiles along the prior beta grain orientations were evaluated in detail. In Figure 8 inverse pole figure (IPF) maps of crack profile 1 (CP1) of specimen 1 and 2 in Figure 6 are shown, together with the IPF color scheme used for the orientation maps in the present study. The prior beta grain boundary is marked PB in the crack profile and based on the IPF maps, the orientation of the columnar prior beta grains is verified and agrees well with the highlighted orientation in Figure 4. Interesting to note is that large areas exhibiting similar crystallographic orientation can be observed along the prior beta grain boundary, which is attributed to the wide columnar alpha present along the grain boundary, as seen in Figure 5.
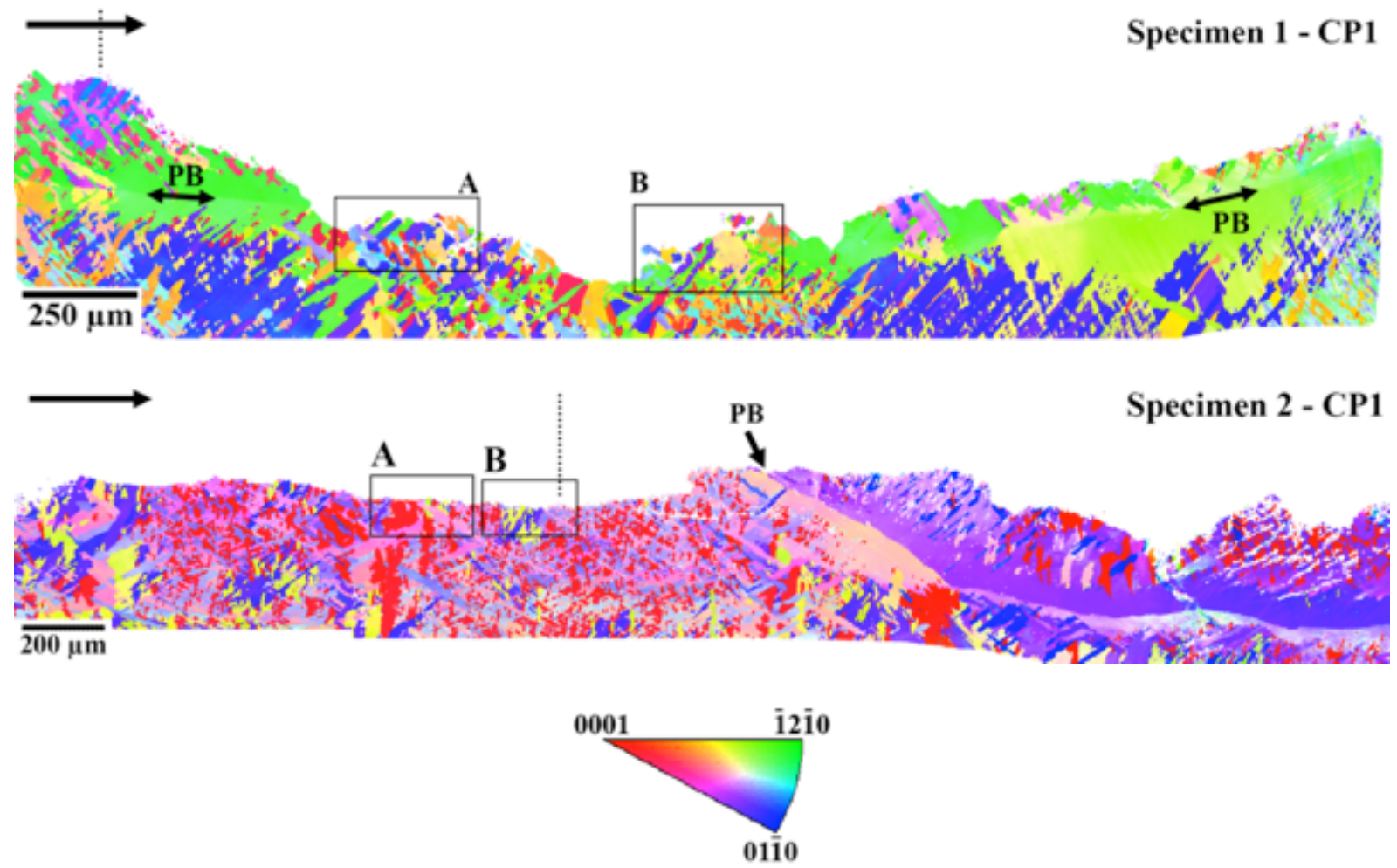

Figure 8. Inverse pole figure maps of the crack profiles $C P 1$ in specimen $1\left(250{ }^{\circ} \mathrm{C}\right)$ and 2 (RT), aligned with the assumed orientation of the columnar prior beta grains based on the findings of the microstructural and fractographic characterization. The length of the precrack is indicated by dotted lines at the crack profile. Crack direction is indicated with black arrows.

When comparing the two crack profiles it can be further observed that the crack profile of specimen 1 is more serrated than that of specimen 2. Also the alpha colony size, which is represented by the different colors in the IPF maps, is different for the two crack profiles; specimen 2 exhibits a finer alpha colony size than specimen 1. It is well known that the alpha colony size is one of the most important microstructural features having impact on the mechanical properties, since its size corresponds to the effective slip length [20], which in this case could explain the more serrated appearance of specimen 1. In Figure 9 the Schmid factors for the primary slip systems are mapped for the two crack profiles, with the loading direction in the vertical direction. A high Schmid factor corresponds to a high resolved shear 
stress, and thus a high probability of slip activity in that slip system. It can be seen that the pyramidal slip system has high intensity along the crack path for both specimens. The c+a slip system is also high in certain areas for both specimens, especially for specimen 1 . The basal slip system shows larger variations in intensity for both specimens and fewer areas with high intensity. The prismatic slip system shows very low Schmid factor intensity for specimen 2 .

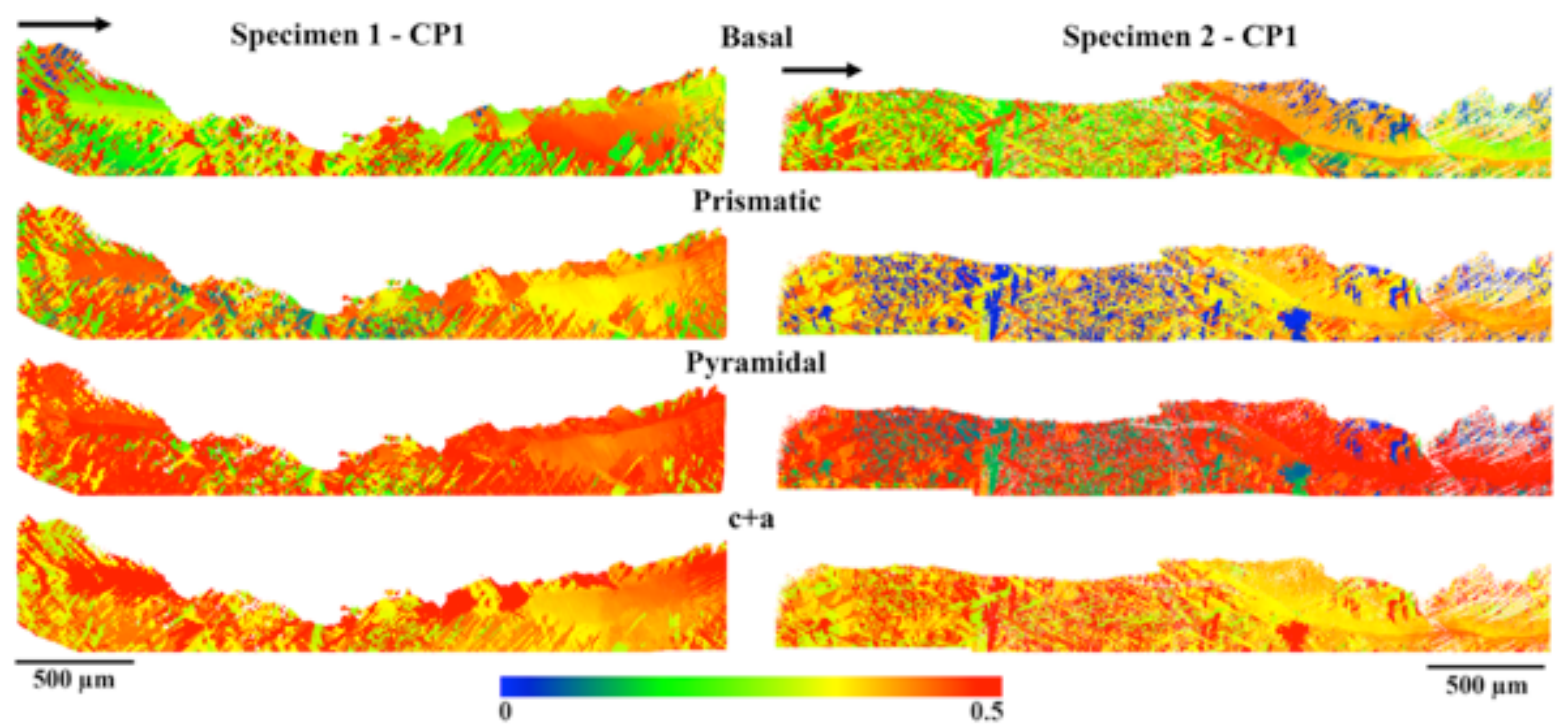

Figure 9. The Schmid factor intensity maps for crack profile 1 of specimen 1 and 2. The black arrows indicate the crack direction.

In Figure 10, at higher magnification of specimen 2 in the squared areas A and B in Figure 8, it can be seen that a smooth crack path is maintained even if the crystal orientation changes along the crack path. This could be explained by the very high Schmid factor intensities available for the specific crystal orientations. For instance, it is clearly seen that for the [0001] orientation (red area), when the load is applied parallel to the $\mathrm{c}$ axis of the hcp crystal structure, the intensity of the c+a slip system is very high, as expected when deforming titanium alloys [21]. Here it could be noted that areas A and B are actually in the pre-crack region. However, for this particular case the pre-cracking and testing load are identical (500 $\mathrm{MPa}$ ), and the distances from the notch to the investigated areas are long enough to avoid any influence from the stress field from the notch. Thus, the only difference between the crack generated under pre-cracking and testing conditions is the frequency $(10$ and $0.5 \mathrm{~Hz}$, respectively). It has been shown previously that the room temperature crack growth rate in forged Ti-6Al-4V at $\mathrm{R}=0.1$ was insensitive to test frequency for waveforms including $0.3 \mathrm{~Hz}$, $25 \mathrm{~Hz}$ and 5 minute dwell at maximum load [22]. Thus, the current difference is not expected to significantly influence slip system activation or crack growth mechanisms, i.e the characteristics of the crack profile. 


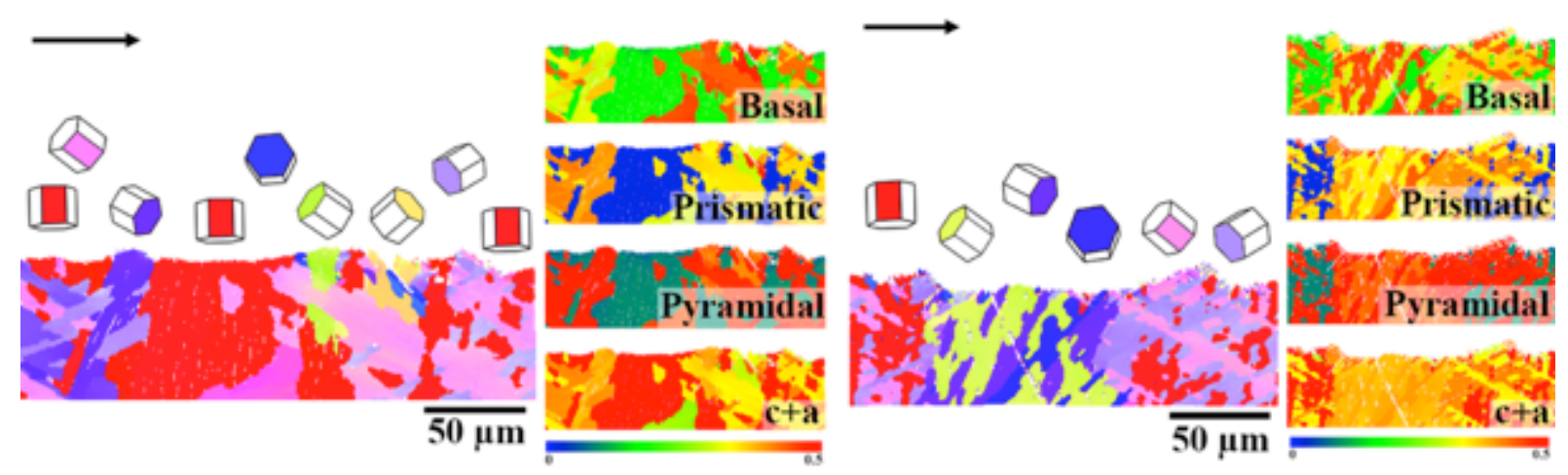

Figure 10. Inverse pole figure maps and the Schmid factor intensity map of the area A (left) and area $B$ (right) of crack profile 1 of specimen 2. The black arrows indicate the crack direction.

Based on the observations it can thus be noted that the combination of fine alpha colony size and crystallographic orientation of specimen 2 are conditions promoting a less serrated crack path and that the crack propagation will continue easily and undisturbed until the conditions change (such as crystallographic orientation and alpha colony size). In other words, this shows that the crack propagation characteristics vary between individual prior beta grains and moreover it can be assumed that the size and orientation of the alpha colonies within the prior beta grains will influence the crack growth characteristics on a local scale. However, the influence of individual prior beta grains on the crack front is not as prominent. During fatigue crack propagation the crack front will strive to remain continuous, which prevents large differences in crack growth rate along the crack front as well as arbitrary crack directions in individual prior beta grains. The characterization of the crack path in the current study is limited to the selected cross sections, in which the crack growth is also affected by the local geometric conditions imposed by the adjacent segments of the crack front. The measured crack growth rate, on the other hand, is the average over the entire crack front, and it is therefore difficult to correlate the local observations of the crack to the crack growth rates in Figure 3.

Specimen 1 and 2 were further evaluated by characterizing the crack profiles CP2A and $\mathrm{CP} 2 \mathrm{~B}$, see Figure 6. Again, the orientation of the prior beta grains is confirmed by the crack profiles for both specimens. Additionally for specimen 1, interesting features along the crack path are observed, see Figure 11. According to the IPF color scheme (in Figure 8), it can be noted that the crack growth direction changes dramatically as the crystal orientation changes to $[\overline{1} 2 \overline{1} 0]$ (green area) in crack profile CP2A. The [1 $2 \overline{1} 0]$-oriented area appears to be a very unfavourable crystallographic orientation for crack propagation, as the crack deflects almost $90^{\circ}$ from the crack path. Interesting to note is that the Schmid factor for basal slip in the [12 10 10]-orientation is close to zero, whereas it is close to maximum in the region just prior to the crack deflection, where the crack propagated perpendicular to the applied load. The Schmid factors for the other systems show the opposite behavior (low in the adjacent region and high in the region that is circumvented by the crack). The fact that the presence of a region where basal slip is hindered poses such an effective obstacle, although slip on all other systems is rather favorable, could indicate that slip on the basal planes is an important part of the crack propagation mechanism. Moreover, a large crack and a lack of fusion (LoF) defect were observed in crack profile $\mathrm{CP} 2 \mathrm{~A}$ and $\mathrm{CP} 2 \mathrm{~B}$, respectively; see squares just below the surfaces in Figure 11. LoF defects could be detrimental to the mechanical properties [9, 23$26]$ and stems from the manufacturing process itself and is related to incomplete melting. The 
formation and characteristics of LoF defects are discussed in detail elsewhere [9]. How the large crack and the LoF defect affect the crack profile will be discussed in later sections.
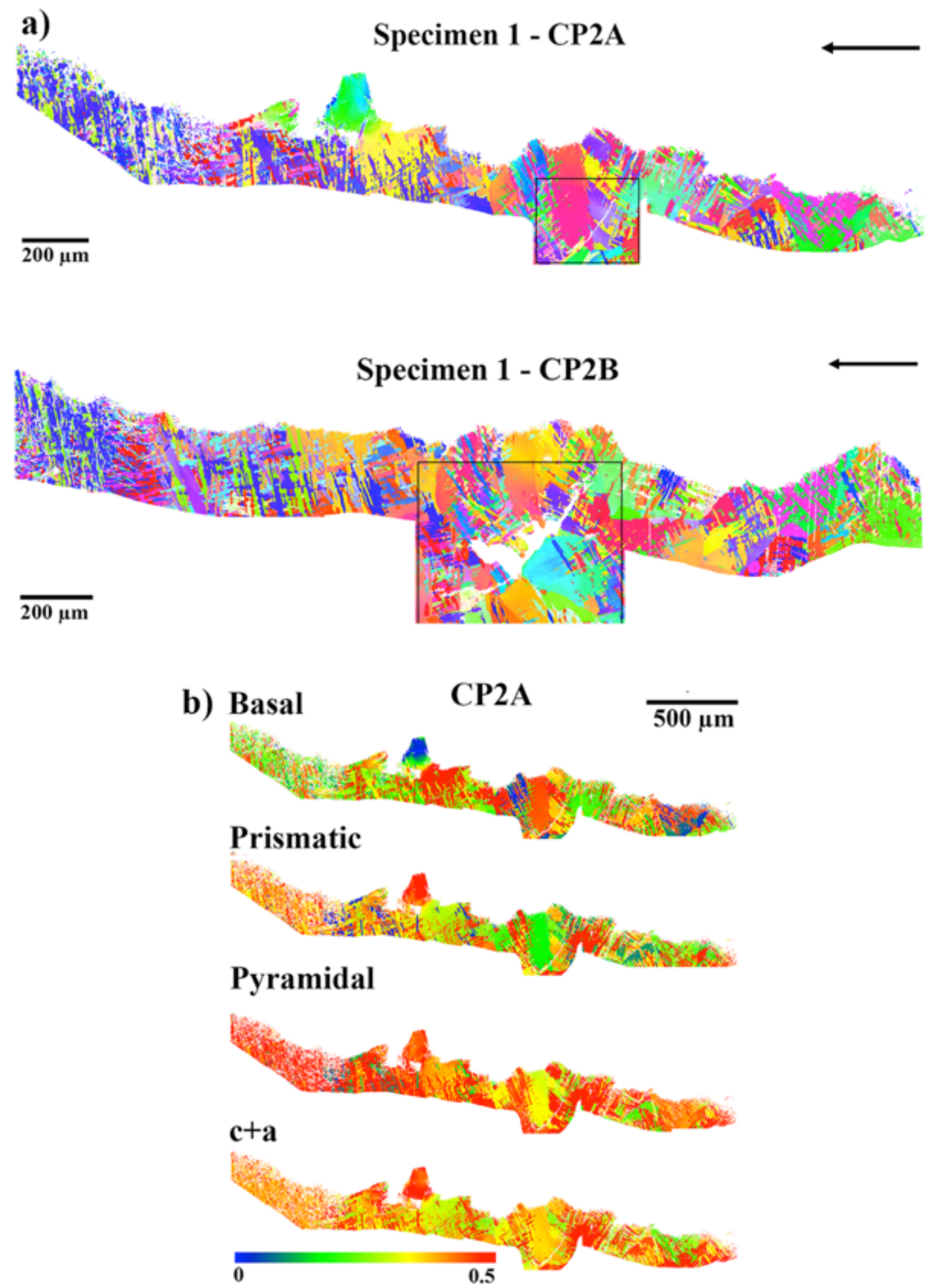

Figure 11. Inverse pole figure maps of crack profile $C P 2 A$ and $C P 2 B$ of specimen 1 (a), located as shown in Figure 6. Schmid factor intensity map of crack profile CP2A (b). The black arrows indicate the crack direction. 
The crack profile of the perpendicular specimen, specimen 3, was also evaluated. Because of the orientation of the prior beta grains, the crack grows through several of them, see Figure 12, where the prior beta grain boundaries are indicated by PB in the IPF map. Even though the crack profile deviates close to some of the prior beta grain boundaries, the crack profile seems to be correlated both to the variation in crystallographic orientation and to the actual boundaries of the prior beta grains. The crystal orientation of the alpha phase is dependent on the crystal orientation of the prior beta phase. The initial alpha laths nucleate at the grain boundary according to the Burgers orientation relationship [27]. However, there are local variations of the crystal orientation of the alpha colonies within the prior beta grains influencing the crack profile as well. In Figure 12 the Schmid factor intensity maps for the crack profile are shown, which clearly indicate that there is no slip system exhibiting high intensity along the whole crack path available. This is connected to the numerous amounts of prior beta grains along the crack profile and the orientations within each grain.
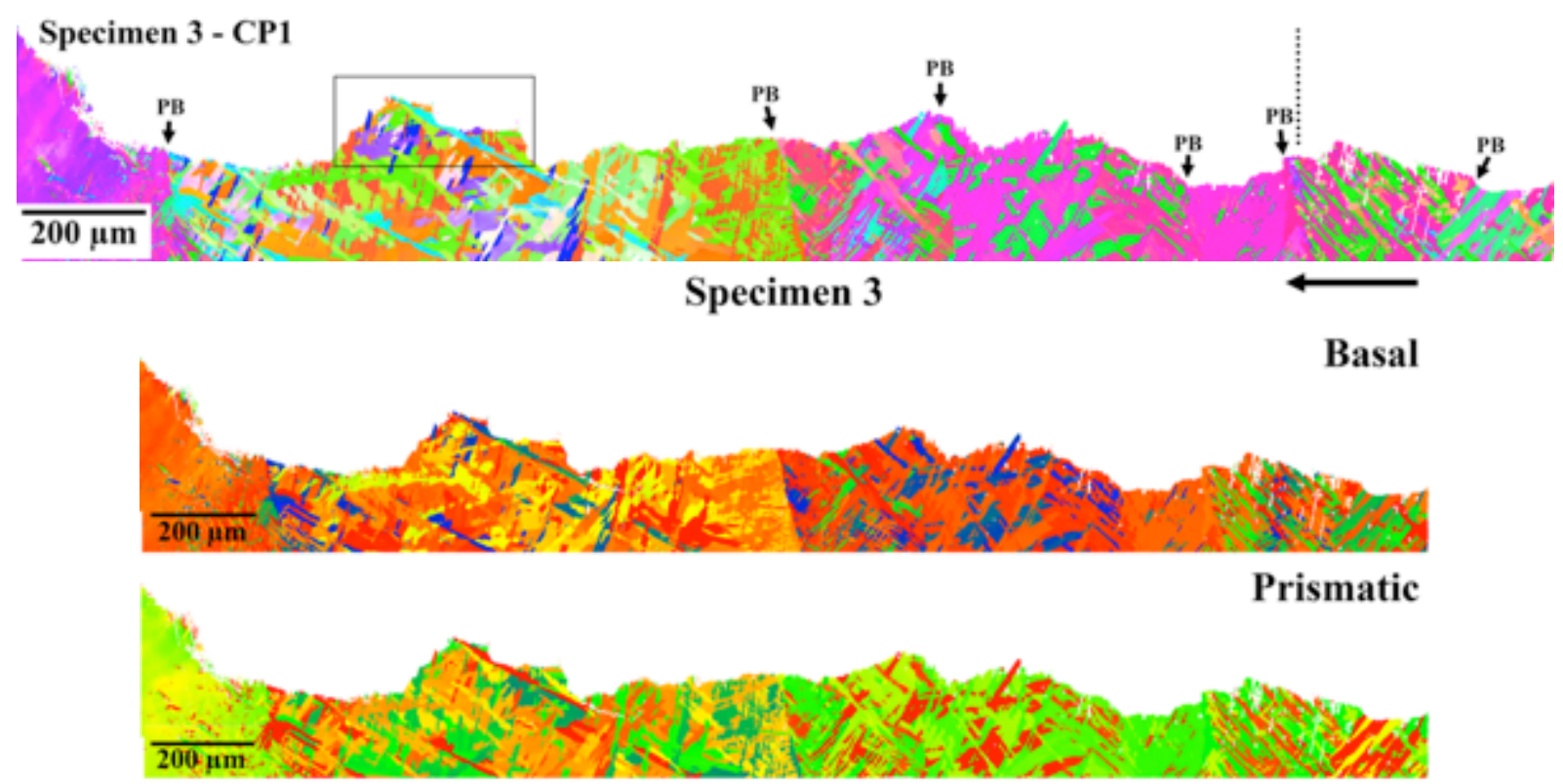

Pyramidal
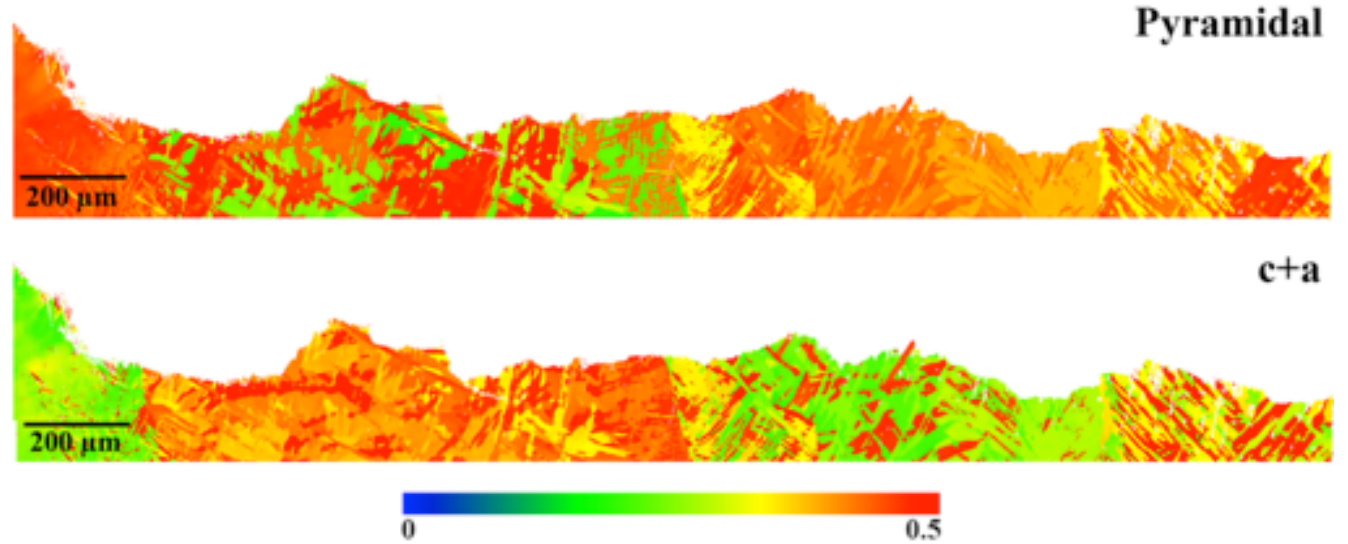

Figure 12. Inverse pole figure map of the crack profile CP1 of specimen 3 passing through several prior beta grains, prior beta grain boundaries (PB), and the Schmid factor intensity maps for the crack profile. The length of the pre-crack is indicated by a dotted line and the black arrows indicate the crack direction.

In Figure 13, selected areas in Figure 8 and 12, for the specimens 1 and 3 are shown, respectively. One common observation for both specimens is that the [0110] orientation (see 
blue areas) or close to [0110] is at the surface of the crack profiles. Together with the observation in Figure 11, showing that the crack deviates around the area exhibiting the

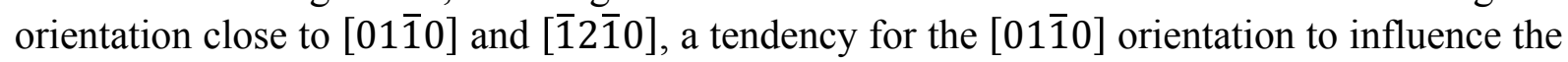
crack path characteristics is observed in the present study.
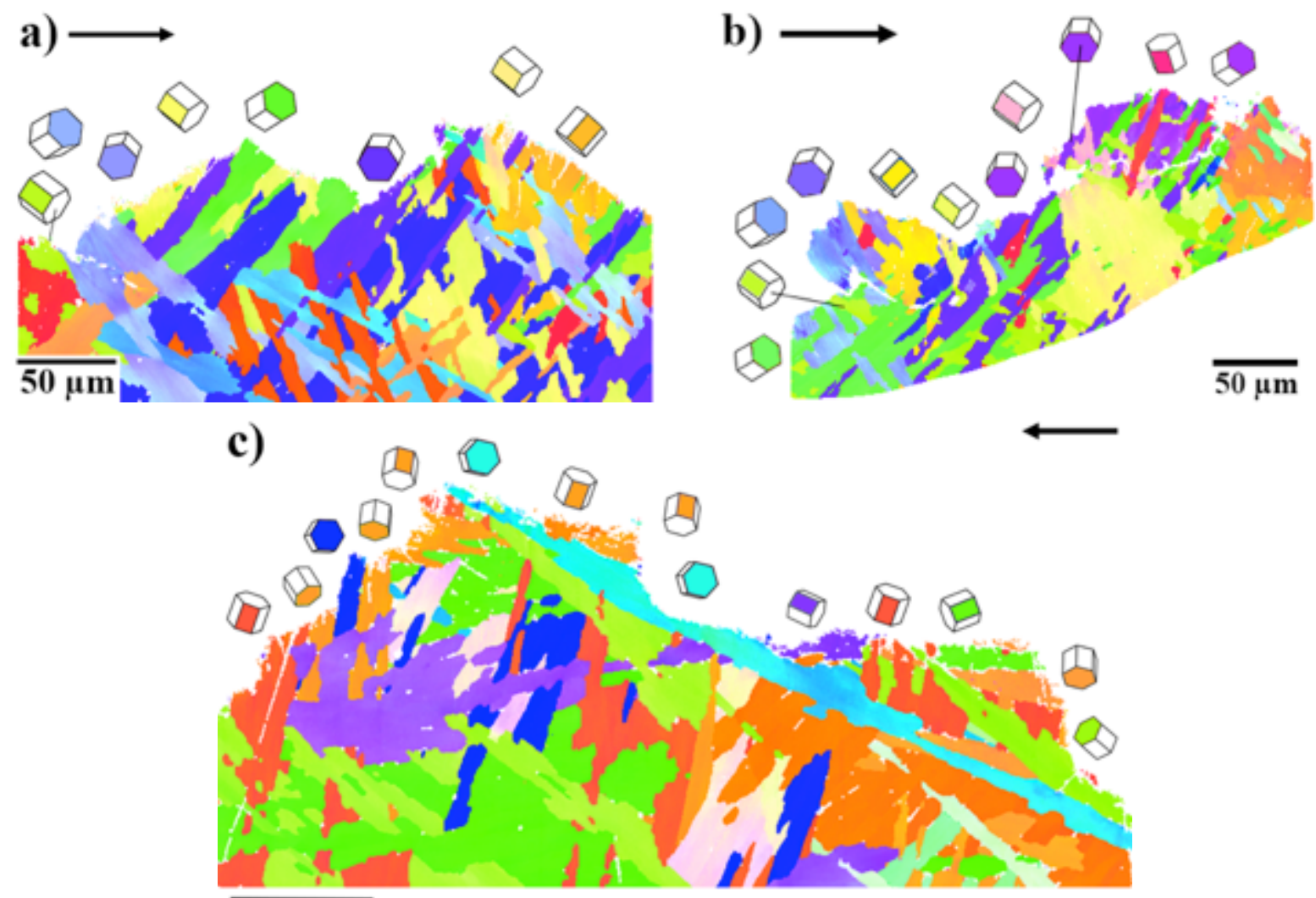

\section{$\mathbf{5 0} \mu \mathrm{m}$}

Figure 13. Inverse pole figure maps showing a) the area $A$ and b) the area $B$ along crack profile CP1 of specimen 1 and c) the highlighted area of the crack profile of specimen 3 . The black arrows indicate the crack growth direction.

Along crack profile CP2B of specimen 1 a large lack of fusion (LoF) defect is observed, (marked with a square in Figure 11). In Figure 14 the IPF map and the local misorientation map around the LoF defect are shown. In the IPF map it is clearly seen that the LoF defect "cuts off" the continuous formation of microstructure during the LMwD process. Small areas of various crystallographic orientations are found around the LoF defect, which refers to the solidification just before the preferably oriented dendrites outgrow the less preferably oriented dendrites. Furthermore, in the local misorientation map, large zones of plastic deformation closest to the free surface of the defect are evident, representing the inhomogeneous stress distribution generated by the LoF defect because of its asymmetrical shape. 

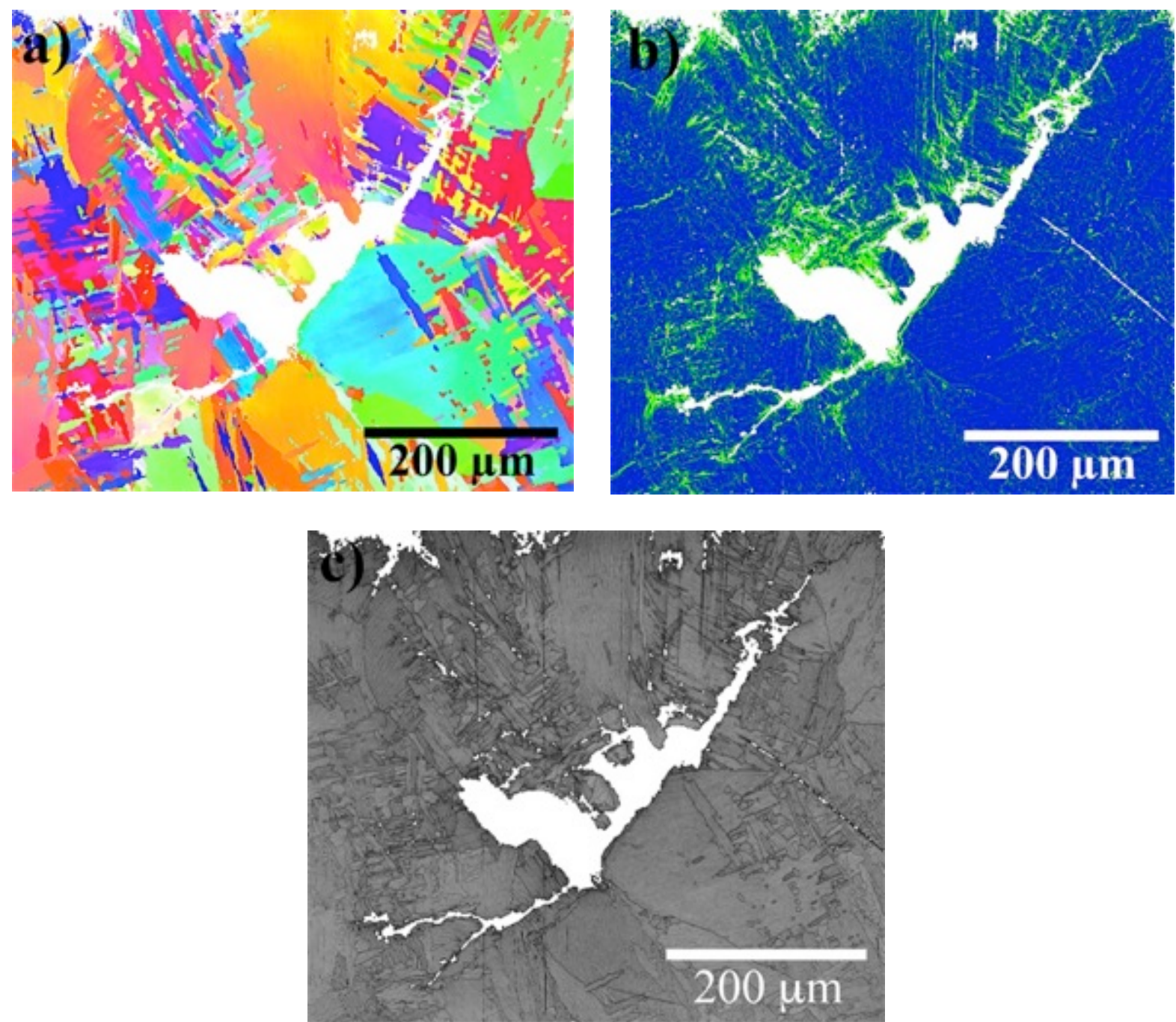

Figure 14. Inverse pole figure map (a), local misorientation map (b) and the image quality map (band contrast) (c) of the lack of fusion defect present in crack profile CP2B of specimen 1.

In the neighboring crack profile CP2A of specimen 1, a large crack is shown (Figure 15). The location of the crack corresponds to the same region as for the LoF defect in crack profile CP2B, i.e. crack profile CP2A was ground approximately $100 \mu \mathrm{m}$, parallel to the location of crack profile CP2B (Figure 14). Because of the location of the crack and its relatively small distance to the LoF defect $(\sim 100 \mu \mathrm{m})$, the crack is most likely connected to the LoF defect. It is further hypothesized that this crack is initiated by the LoF defect, which in that case indicates the detrimental influence from the LoF defects. Interesting to note is that the crack is almost parallel to the basal planes (see pink and purple area in Figure 15). According to the Schmid factor intensity in Figure 15 it can moreover be seen that the basal slip system shows high intensity at least for part of the crack. In the local misorientation maps there are areas indicating more deformation, i.e. slip activity. For instance, it is seen that slip is occurring in areas quite far away from the crack, indicated by the white arrows to the left in the local misorientation map in Figure 14. In the Schmid factor intensity maps it can further be observed that these areas correspond to a very high intensity of the prismatic and $\mathrm{c}+\mathrm{a}$ slip systems. 

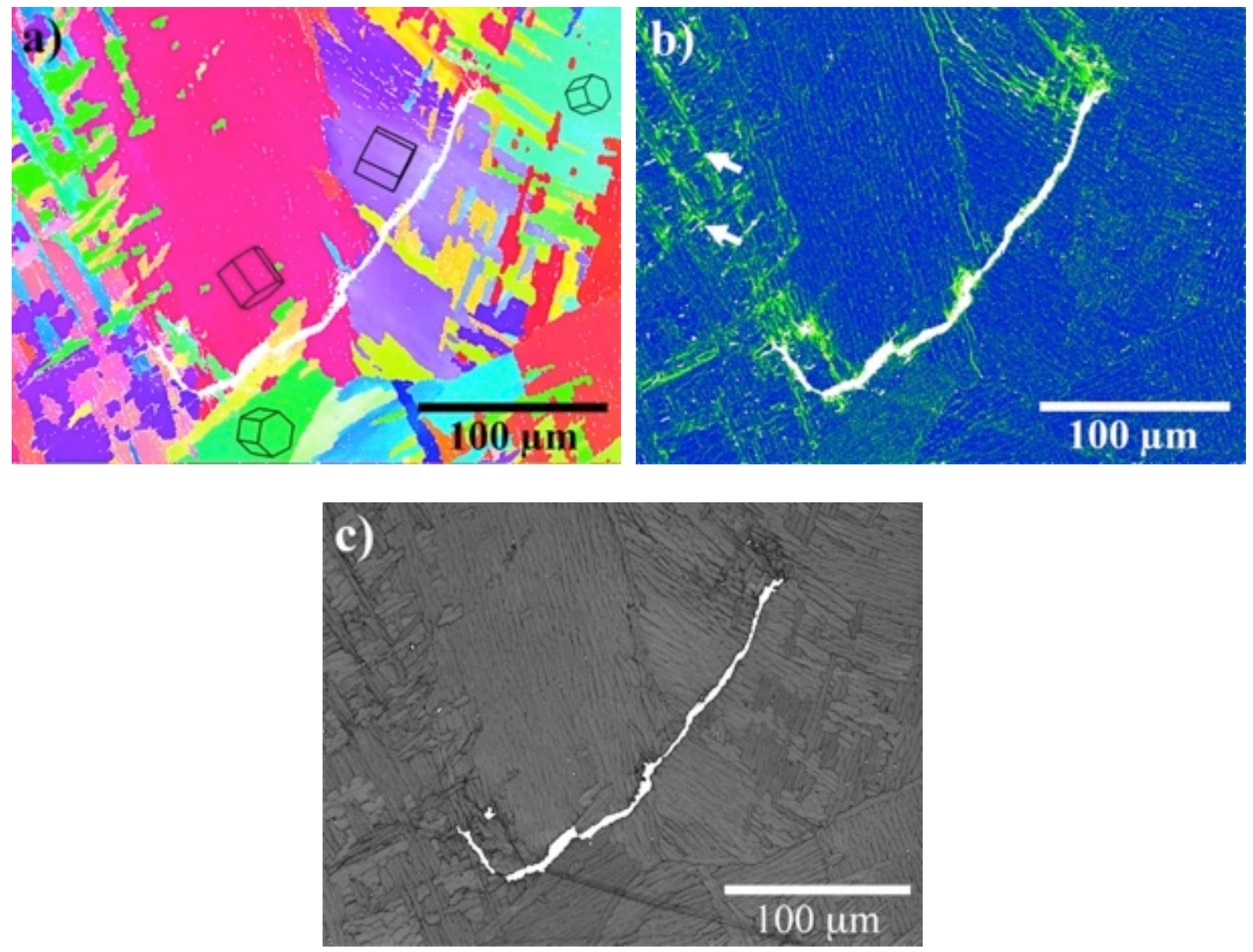

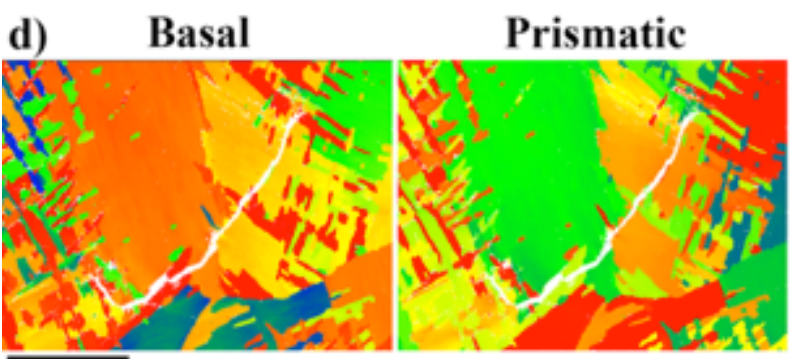

$100 \mu \mathrm{m}$

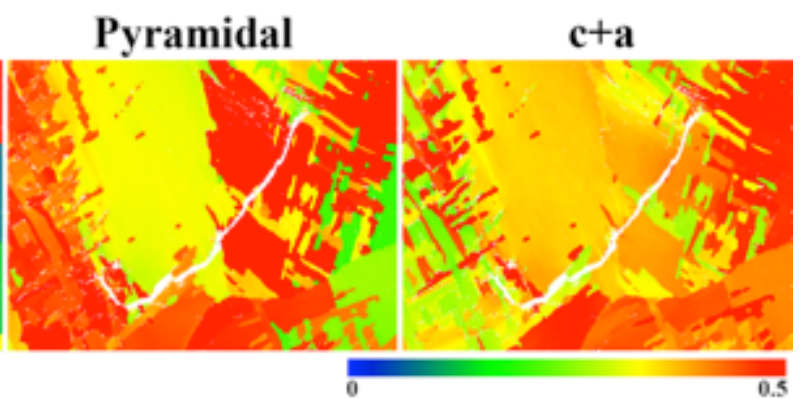

Figure 15. The large crack present in crack profile CP2A of specimen 1. Inverse pole figure map (a), local misorientaion map (b), image quality map (band contrast) (c) and Schmid factor intensity maps $(d)$.

\section{Conclusions}

Based on the selected specimens and their crack profiles in the present study the following conclusions can be made:

- No significant difference in the fatigue crack growth rate was confirmed for the two specimen orientations and there was no difference between room temperature and $250^{\circ} \mathrm{C}$.

- The fractography reveals a difference in tortuosity within the crack propagation areas for all specimens and could be related to the alpha colonies in the prior beta grains. This difference in tortuosity was more pronounced for the parallel specimens.

- Large areas exhibiting similar crystallographic orientation were observed along the prior beta grain boundaries, which were attributed to the wide alpha colonies frequently observed along the prior beta grain boundaries. 
- The Schmid intensity factor for the pyramidal slip system was high along the crack profiles of the parallel specimens. A larger variation in Schmid intensity factor was observed for the slip systems in the perpendicular specimen.

- Large areas of local misorientation were observed in regions around a LoF defect, which indicate the inhomogeneous stress distribution occurring around these asymmetrical defects.

\section{Acknowledgements}

The authors would like to acknowledge the Graduate School of Space Technology for supporting and encouraging the project. The authors are also grateful for the financial support from NFFP (the National Aviation Engineering Research Program) in Sweden.

[1] R. R. Boyer, "Attributes, characteristics, and applications of titanium and its alloys," JOM, vol. 62, pp. 21-24, 2010.

[2] I. Gibson, D. W. Rosen and B. Stucker, Additive Manufacturing Technologies Rapid Prototyping to Direct Digital Manufacturing. New York: Springer, 2010.

[3] W. U. H. Syed, A. J. Pinkerton and L. Li, "A comparative study of wire feeding and powder feeding in direct diode laser deposition for rapid prototyping," Applied Surface Science, vol. 247, pp. 268-276, 2005.

[4] B. Baufeld, E. Brandl and O. van der Biest, "Wire based additive layer manufacturing: Comparison of microstructure and mechanical properties of Ti-6Al-4V components fabricated by laser-beam deposition and shaped metal deposition," Journal of Materials Processing Technology, vol. 211, pp. 1146-1158, 2011.

[5] E. Brandl, C. Leyens and F. Palm, "Mechanical properties of additive manufactured ti$6 \mathrm{Al}-4 \mathrm{~V}$ using wire and powder based processes," in 2009, .

[6] P. Åkerfeldt, R. Pederson and M. Antti, "Microstructure and mechanical properties of laser metal depostited ti-6Al-4V," in Beijing, China, 2012, pp. 1730-1730-1734.

[7] B. E. Carroll, T. A. Palmer and A. M. Beese, "Anisotropic tensile behavior of Ti-6Al-4V components fabricated with directed energy deposition additive manufacturing," Acta Materialia, vol. 87, pp. 309-320, 2015.

[8] G. P. Dinda, L. Song and J. Mazumder, "Fabrication of Ti-6Al-4V scaffolds by direct metal deposition," Metall Mater Trans A, vol. 39A, pp. 2914-2922, 2008.

[9] P. Åkerfeldt, R. Pederson and M. Antti, "A fractographic study exploring the relationship between the low cycle fatigue and metallurgical properties of laser metal wire deposited Ti6Al-4V," International Journal of Fatigue, vol. 87, pp. 245-256, 2016.

[10] P. Åkerfeldt, M. Antti and R. Pederson, "Influence of microstructure on mechanical properties of laser metal deposited Ti-6Al-4V", Materials Science \& Engineering A, vol. 674, pp. 428-437, 2016. 
[11] E. Brandl, B. Baufeld, C. Leyens and R. Gault, "Additive manufactured Ti-6Al-4V using welding wire: comparison of laser and arc beam deposition and evaluation with respect to aerospace material specifications," Physics Procedia, vol. 5, pp. 606, 2010.

[12] S. Leuders, M. Thöne, M. Riemer, T. Niendorf, T. Tröster, H. A. Richard and H. J. Maier, "On the mechanical behaviour of titanium alloy TiAl6V4 manufactured by selective laser melting: Fatigue resistance and crack growth performance," International Journal of Fatigue, vol. 48, pp. 300-307, 2013.

[13] A. Riemer, H. A. Richard, J. -. Bruggemann and J. -. Wesendahl, "Fatigue crack growth in additive manufactured products," Frattura Ed Integrità Strutturale, vol. 34, pp. 437-446, 2015.

[14] P. Edwards and M. Ramulu, "Effect of build direction on the fracture toughness and fatigue crack growth in selective laser melted Ti-6Al-4V," Fatigue and Fracture of Engineering Materials and Structures, vol. 38, pp. 1228-1236, 2015.

[15] P. A. Kobryn and S. L. Semiatin, "Mechanical properties of laser-deposited ti-6Al-4V," in 2001, pp. 179-186.

[16] M. Seifi, M. Dahar, R. Aman, O. Harrysson, J. Beuth and J. J. Lewandowski, "Evaluation of orientation dependence of fracture toughness and fatigue crack propagation behaviour of as-deposited ARCAM EBM Ti-6Al-4V," The Journal of the Mineral, Metals \& Minerals Society (TMS), vol. 67, pp. 597-607, 2015.

[17] Y. Zhai, H. Galarraga and D. A. Lados, "Microstructure evolution, tensile properties, and fatigue damage mechanisms in Ti-6Al-4V alloys fabricated by two additive manufacturing techniques," Procedia Engineering, vol. 114, pp. 658-666, 2015.

[18] R. Pederson, O. Babushkin, F. Skystedt and R. Warren, "Use of high temperature x-ray diffractometry to study phase transitions and thermal expansion properties in Ti-6Al-4V," Materials Science \& Technology, vol. 19, pp. 1533-1538, 2003.

[19] A. Coles, R. E. Johnson and H. G. Popp, "Utility of surface-flawed tensile bars in cyclic life studies," Journal of Engineering Materials and Technology, vol. October, pp. 305-315, 1976.

[20] G. Lutjering, "Influence of processing on microstructure and mechanical properties of (alpha+beta) titanium alloys," Mater Sci Eng A, vol. 243, pp. 32, 1998.

[21] G. Lutjering and J. C. Williams, Titanium. Berlin: Springer-Verlag, 2003.

[22] C.A. Stubbington and S. Pearson, "Effect of dwell on the growth of fatigue cracks in Ti6Al-4V alloy bar," Engineering Fracture Mechanics, vol. 10, pp. 723-756, 1978.

[23] Q. Liu, J. Elambasseril, S. Sun, M. Leary, M. Brandt and P. Khan Sharp, "The effect of manufacturing defects on the fatigue behaviour of ti-6Al-4V specimens fabricated using selective laser melting," in 2014, pp. 1519-1524. 
[24] L. E. Murr, S. A. Quinones, S. M. Gaytan, M. I. Lopez, A. Rodela, E. Y. Martinez, D. H. Hernandez, E. Martinez, F. Medina and R. B. Wicker, "Microstructure and mechanical behavior of Ti-6Al-4V produced by rapid-layer manufacturing, for biomedical applications," Journal of the Mechanical Behaviour of Biomedical Materials, vol. 2, pp. 20-32, 2009.

[25] T. Vilaro, C. Colin and J. D. Bartout, "As-fabricated and heat-treated microstructures of the Ti-6Al-4V alloy processed by selective laser melting," Metall Mater Trans A, vol. 42A, pp. 3190-3199, 2011.

[26] G. Kasperovich and J. Hausmann, "Improvement of fatigue resistance and ductility of TiAl6V4 processed by selective laser melting," Journal of Materials Processing Technology, pp. 202-214, 2015.

[27] W. G. Burgers, "On the process of transition of the cubic-body-centered modification into the hexagonal-close-packed modification of zirconium," Physica, vol. 1, pp. 561-586, 1934. 